bottle-preparations of the soft parts, and several dry preparations, all of which are in the galleries and osteological cases of the museum. Since the time of IIunter, great advances have been made in cetology. Cuvier, Van Beneden, Eschricht, and many others, have worked at the subject; new species have been found almost every year, and are being brought to our knowledge by zoologists of various parts of the world.

The cetacea are true mammalia, and their fish-like appearance is only an adaptation by nature to fit them for living in the water. They are a very specialised order, and cannot be mistaken for any other animals; unlike most orders, they present no transitional forms. Their general external fish-like appearance; the large size of the head, placed on the anterior end of the trunk, without the external sppearance of the intervention of neck, with one exception; and the posterior end of their body terminating in a horizontally fattened fin, distinguish them from all other animals. Their only external limbs are the anterior ones, which are reduced to paddles, without any appearance of fingers or naiss, and with little or no motion of the elbow-joint. Though there is no trace of hind limbs to be seen externally, yet, in some species of whales, they are to be found under the skin in a very rudimentary form. The external surface of these animals is covered over with a smooth shining skin, from which all hair or anything to obstruct their passage through the water is alosent. The only portion of the body on which hair sometimes exists is about the mouth; here a feo bristles may re found situated at intervals apart. The animal heat, which in most other mammals is principally retained within the body by a coat of hair or fur, is retained within the whale's body by a thick layer of a particular kind of fat called blubber, situated immediately under the skin. Many of the whales possess a dorsal fin, which gives them a still more fish-like appearance. This fin is, however, not a true fin, but only a fold of skin with an intervening layer of blubber; no trace of it is to be seen in the skeleton. The jaws have teeth set in the gums, or a peculiar substance, arranged in plates hanging downwards from each side of the palate, called baleen or whalebone, though structurally it is entirely different from bone. The presence of either teeth or of whalebone is the basis of the classification of the whales into two great groups. All whales possess a blow-hole, which may be single or double, united or separate, sttuated on the highest part of the head. Regarding the breathing of whales, erroneous opinions have frequently been entertained. Many persons have imagined that, along with the breath, water is discharged through the blow-hole, causing what is familiarly known as the spouting of whales. The whale never spouts water through his blow-hole, but only exhales air highly charged with moisture, the same as any other mammal. When the sea is caln, and the weather still and frosty, the expired air can be seen rising at the spots where he comes to the surface to breathe, like puffs of steam. This is due to the air having been heated while in the animal's lungs to a considerably higher temperature than that of the surrounding atmosphere. What has led to the belief that the whale discharges water from his blow-holes, is probably the fact that, not unfrequently, he expires before his head is entirely above the surface of the water, the result being that water in the form of foam is driven upwards into the air along with the breath; this phenomenon is especially noticeable when the sea is rough. Another circum. stance which has led to the fallacy is that, when harpooned, the whale frequently spouts blood through the blow-hole. The cause of this is, however, entirely different, as in this case the blood comes from the injured lung. Cetaceans all feed on animal food, principally fish also on cephalopods, crustaceans, octopuses, etc. Only the grampus will eat the flesh of warm-blonded animals and seals. Whales are to be found in all seas and in all parts of the ocean. There are some forms which only frequent large rivers, such as the Indus and Amazcn.

\section{THE ANTISEPTIC TREATMENT OF ENTERIC FEVER}

\section{By C. E. SIIELLY, M.B.Cantab., Ifertford.}

In the London Midical Record for August 1880 appeared a risume of the papers published by Dr. C. G. Rothe in the Deutsche Medicinische Wochensclirift, Nos. II and 12 , on the treatment which he had success. fully employed in enteric fever. This consisted essentially in the ad: ministration of carbolic acid and tincture of iodine in frequently repeated doses until apyrexia was produced; and thereafter, at longer intervals, for two or three weeks. The advantages claimed were, rapid and permanent subsidence of the high temperature, and of the vascular excitement (the pulse usually falling before the temperature, and often temaining subnormal in frequency for weeks, but not becoming irregular or intermittent); early subsidence of the gastric symptomis (by the beginning of the second week at latest); after which the patient gained a moderate appetite, and always experienced "a feeling of being quite comfortable"; and uninterrupted convalescence followed. Finally, Dr. Rothe expressed his wish that all who deemed his treatment worth a trial would publish their results, in order that his own observations might be confirmed or corrected.

In a short series of cases of enteric fever which came under my observation a few months since, Dr. Rothe's treatment, slightly modified, was put in practice, with resalts which were not less gratifying to the patients, I believe, than to myself. I should state at once that all the subjects were young people, their ages ranging from sixteen to twenty-seven years; that none of the cases-with one exception, in which the morning temperature during the first three days on which it was observed, fluctuated betiveen $104.7^{\circ}$ and $105.2^{\circ} \mathrm{F}$.- were of more than medium severity at the outset; and that the surrounding hygienic conditions were, in all cases, good. Humanly: speaking, all the patients would probably have recovered under any form of rationa treatment, combined with good and careful nursing. But I was struck by the early and rapid fall of temperature, the retardation and steadying of the pulse, the quickness with which the motions lessened in number and improved in quality, the cleanly tongue, the absence of sordes, the early removal of the abdominal pain and tendemess, the refreshine sleep, the comparatively slight emaciation, and the remarkable unanimity with which all the patients agreed in expressing themselves as feeling quite comfortable after the first few doses of the remedy. No increase. of temperature was observed to attend the cruptions of the five successive crops of spots which appeared in the most severe case. No complications were noted.

So small a record of mild cases would be scarcely worth quoting in extenso; but, so far as I have been able to test this remedy, it has certainly proved reliable; and I shall be glad to know whether any others find, or have found, it valuable under circumstances more trying than those to which I have had an opportunity of applying it. The theory on which Dr. Rothe founds the name of his "antiseptic (antizymotic) treatment" is that to which the recent discoveries of Professor Klebs (A rchiv fïr Experim. Pathologie, vol. xii, parts 2 and 3 ) give increased importance; and it would be most interesting to find how far the theoretical link between the control of the pyrexia and other symptoms of enteric fever, and the simultarieous administration of an antiseptic medicine would be strengthened, or the reverse, by the systematic examination of the blood and tissues of such patients, after the method of Klebs. The formula recommended by Dr. Rothe is one to two parts of carbolic acid and one of tincture of iodine in one hundred and twenty of water; one tablespoonful to be given hourly until a decided effect is produced on pulse and temperature; thence every two hours until apyrexia follows; and it should be continued for two or: three weeks. Under these circumstances, it is not surprising that, "after two or three weeks' uninterrupted administration, toxic symptoms' always occurred". In my cases, a draught containing one or two minims of carbolic acid, one to three minims of tincture of jodine, half a drachm of simple syrup, and an ounce of lemon-water; was given every two, three, or four hours, or even less often, without any untoward symptoms, and with satisfactory results. Dr. Rothe recommended oil of peppermint as effectually disguising the fiavour of the principal ingredients; but, following out a hint derived from the publication of Lebon's formula, I found essence of lemon even more effectual to this end, and more generally agreeable; and in some cases small doses of nux vomica and of nitro-hydrochloric acid were added to the mixture towards the termination of the disease.

I have mentioned the comparatively slight emaciation; the rapidity with which both fiesh and strength were regained was in proportion; and the appetite, although it returned very early in the disease, never attained that craving character which is sometimes an almost painful experience in the convalescence from enteric fever.

I may add that this combination has yielded me good results in cases of choleraic and autumnal diarrhoea, with or without high temperature: Dr. Rothe says that, for the last ten years, he has not ventured to give up its use in phthisis, diarrhcea, diphtheria, etc.

Presextarion.-Mr. Whitfield Perkins, üpon recently resigning the appointment of Assistant Medical Officer to the City of Liondon Lunatic Asylum, at Stone, near Dartford, was presented with many gratifying testimonials by the officars and employés of the institution, including a pony-carriage, a tea-pot and a coffee-pot, a cruet-stand, a spoon-warmer, a glass centre, a polyglot Bible, a butter-dish and knife, a set of salt-cellars, two pairs of vases, and a case of fish knives and forks-having upon it a suitable inscription, subscribed for by the attendants and artisans. 